University of Nebraska - Lincoln

DigitalCommons@University of Nebraska - Lincoln

1996

\title{
Novel Algorithms for Remote Sensing of Chlorophyll Content in Higher Plant Leaves
}

Anatoly A. Gitelson

University of Nebraska - Lincoln, agitelson2@unl.edu

Mark N. Merzlyak

Moscow State University

Yuri Grits

Ben-Gurion University of the Negev

Follow this and additional works at: https://digitalcommons.unl.edu/natrespapers

Part of the Natural Resources and Conservation Commons

Gitelson, Anatoly A.; Merzlyak, Mark N.; and Grits, Yuri, "Novel Algorithms for Remote Sensing of Chlorophyll Content in Higher Plant Leaves" (1996). Papers in Natural Resources. 238.

https://digitalcommons.unl.edu/natrespapers/238

This Article is brought to you for free and open access by the Natural Resources, School of at DigitalCommons@University of Nebraska - Lincoln. It has been accepted for inclusion in Papers in Natural Resources by an authorized administrator of DigitalCommons@University of Nebraska - Lincoln. 


\title{
Novel algorithms for remote sensing of chlorophyll content in higher plant leaves
}

\author{
Anatoly A. Gitelson ${ }^{1}$, Mark N. Merzlyak ${ }^{2}$ and Yuri Grits ${ }^{1}$ \\ ${ }^{1}$ Remote Sensing Laboratory, J. Blaustein Institute for Desert Research, Ben-Gurion University of the Negev, Sede- \\ Boker Campus 84993, Israel. Phone: (972)-7-557 219; Fax: (972)-7-557 042; E-mail: gitelson@bgumail.bgu.ac.il \\ ${ }^{2}$ Department of Cell Physiology and Immunology, Faculty of Biology, Moscow State University, 19899 GSP Moscow \\ W-234, Russia. Phone: (007) 095-9392587; Fax: (007) 095-9393807; E-mail: merzlyak@ biophys.bio.msu.su
}

\begin{abstract}
The general features of reflectance spectra of higher plant leaves are considered with special reference to remote sensing of chlorophyll. Wavelengths with maximum sensitivity to chlorophyll content were found in the wide spectral range from 550 to $630 \mathrm{~nm}$ and near $700 \mathrm{~nm}$. The wavelength of the red edge position of the reflectance spectrum correlated very closely with the reflectance at 550 and $700 \mathrm{~nm}$. The ratios of reflectances in the near infra-red range of the spectrum (above $750 \mathrm{~nm}$ ) to that at $700 \mathrm{~nm}$ $\mathrm{R}_{\mathrm{NIR}} / \mathrm{R}_{700}$ and $\mathrm{R}_{\mathrm{NIR}} / \mathrm{R}_{550}$ were directly proportional to the leaves' chlorophyll content. Newly introduced algorithms make it possible precise chlorophyll estimation (with an error of less than $5 \mathrm{nmol} / \mathrm{cm}^{2}$ ) and probably could be applied to a number of plant species. They exhibit more than 6 times wider dynamic range than the widely used Normalized Difference Vegetation Index.
\end{abstract}

\section{INTRODUCTION}

The content of chlorophyll $(\mathrm{Chl})$ in higher plant leaves changes throughout different stages of plant development and is affected when terrestrial vegetation is exposed to various kinds of natural and anthropogenic stresses. Remote determination of $\mathrm{Chl}$ content from near and far distance by non-invasive methods is therefore a good mean to detect physiological states and stress conditions in plants. Recently as a result of signature analysis of reflectance spectra of two deciduous species maple and chestnut [2-4] and tobacco plants growing under controlled conditions [7], several indexes were developed. It allowed precise Chl determination in the leaves in a wide range of pigment variation (from dark green to yellow). On the basis of these findings, a novel atmospheric resistant index for remote sensing of Chl was developed [5]. In addition, it was found that reflectance at $700 \mathrm{~nm}$ is strongly related to the red edge position in leaf reflectance spectra that can be also used in remote leaf pigment analysis [6,7].

The aim of this study was to examine whether the newly established indices are accurate in quantifying of Chl content in several other plant species growing in a different climatic environments.

\section{METHODS}

Maple and chestnut leaves were collected in Moscow from spring to late autumn and the data set covered all stages of leaf development and senescence [2, 3]. Cotoneatser leaves were collected during autumn. Pigment analysis was carried out as described previously $[2,3]$. Spectral and Chl data for tobacco plants (both green and aurea mutant) were published in [7]. The leaves of fig, oleander, hibiscus, vine and rose plants were collected during winter 1995/96 in Sede-Boker Campus of Ben-Gurion University of the Negev (Israel).

Reflectance spectra for maple, chestnut and cotoneatser leaves were measured with a Hitachi 150-20 spectrophotometer equipped with an integrating sphere as described in details previously [2]. In experiments carried out in Israel a LICOR-1800 spectral radiometer with integrating sphere attachment LI-1800-12S with spectral resolution of 2 nm was used.

\section{RESULTS AND DISCUSSION}

The spectra of standard deviation of reflectance for dark green to yellowish-green leaves of different and non-related species and from different climatic regions revealed common spectral features (Fig. 1). In all cases (see also [2]) a minimum sensitivity to pigment variation was found between 400 and $500 \mathrm{~nm}$ and near $676 \mathrm{~nm}$. Two distinct maxima of standard deviation were localized in a broad spectral band from 550 to $600 \mathrm{~nm}$ and in a relatively narrow band near 700 nm.

Consistent and diagnostic behavior of reflectance spectra in the red edge range (680 to $750 \mathrm{~nm}$ ) was observed for leaves of maple, chestnut and tobacco plants $[6,7]$. These included the wavelength position of the red edge and the reflectance in the range from 690 to $710 \mathrm{~nm}$. Both characteristics were found to be dependent on chlorophyll concentration. The wavelength of the red edge position of the reflectance spectrum (inflection point) correlated very closely with the leaves' chlorophyll content in a curvilinear manner. The data in Fig. 2 indicate that the reflectance near $700 \mathrm{~nm}$ is a sensitive indicator of the red edge position and can be used for Chl determination in higher plant leaves. 


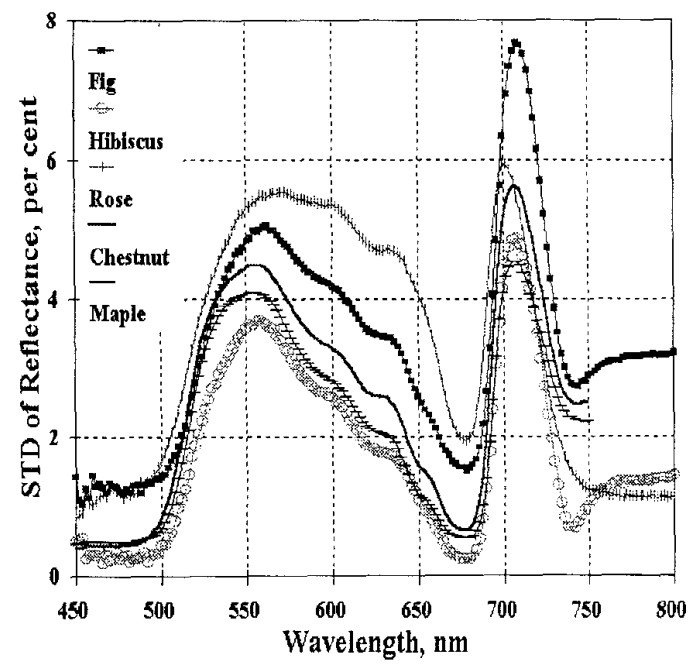

Fig. 1. Standard deviation of reflectance of the leaves with chlorophyll content $>5 \mathrm{nmol} / \mathrm{cm}^{2}$.

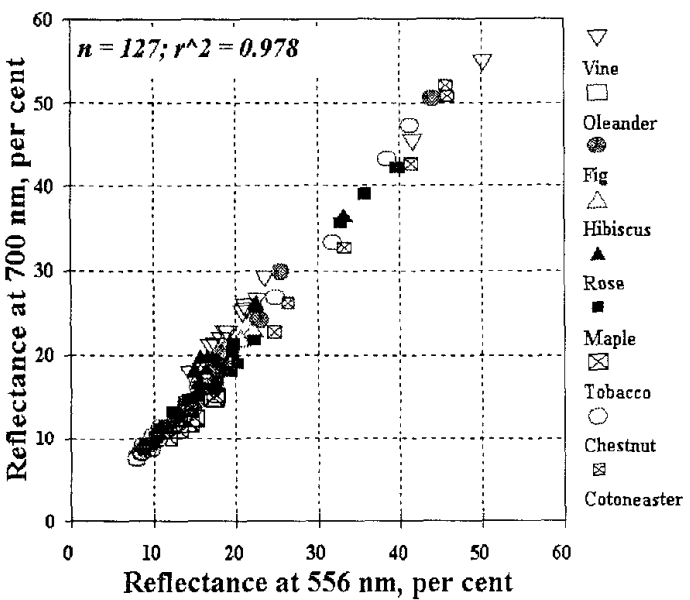

Fig. 3. Relationship of reflectances at 700 and $556 \mathrm{~nm}$ for the leaves of different plant species with chlorophyll a content from 0.3 to $45 \mathrm{nmol} / \mathrm{cm}^{2}$. The square of the correlation coefficient was $r^{2}=0.978$ for all 127 leaves studied.

Maximum sensitivity to variation in $\mathrm{Chl}$ content was found in the green and red (near $700 \mathrm{~nm}$ ) ranges of the spectrum (Fig. 1). As for soybean [1], maple, chestnut [4] and tobacco [7] leaves, reflectances at 700 and $550 \mathrm{~nm}$ correlated very closely for other species studied (Fig. 3). This phenomenon

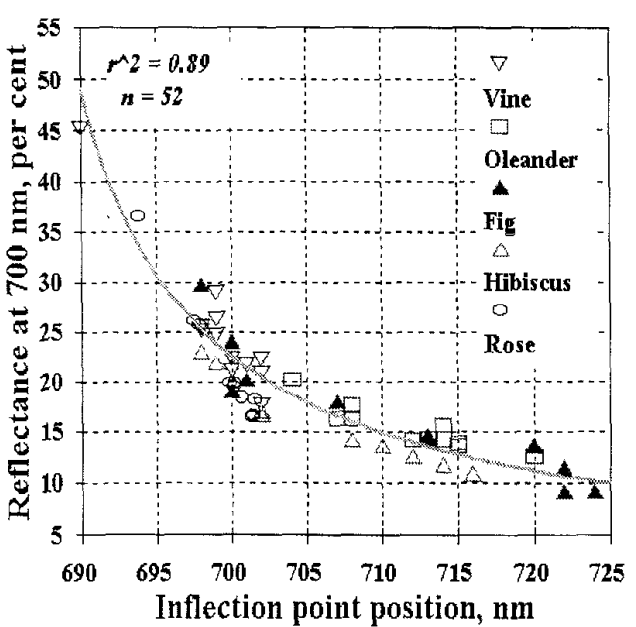

Fig. 2. Wavelength of the inflection point position (the peak at the 1 st derivative of reflectance) versus the reflectance at 700 $\mathrm{nm}$ for five unrelated plant species. Solid line represents hyperbolic relationship with the coefficient of determination $r^{2}$ $>0.89$.

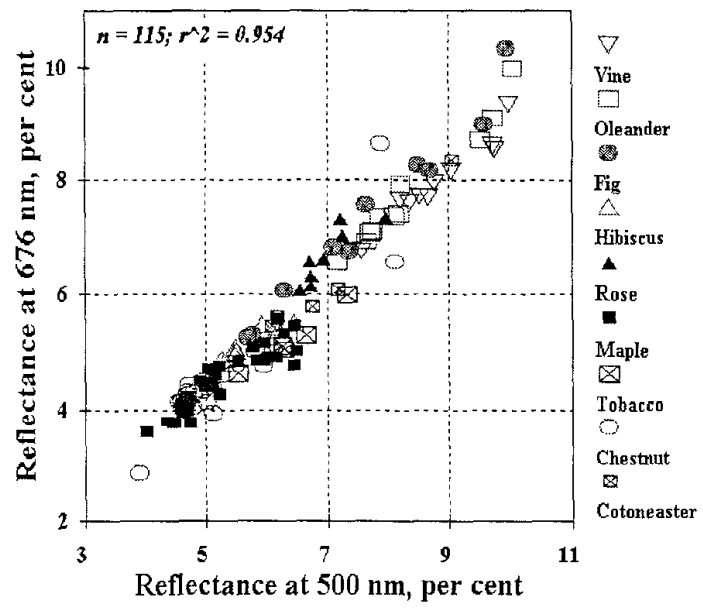

Fig. 4. Relationship of the reflectance at $500 \mathrm{~nm}$ with that at $670 \mathrm{~nm}$ for 115 studied leaves with chlorophyll $a$ content from 5 to $45 \mathrm{nmol} / \mathrm{cm}^{2}$. The solid line presents a linear relationship with the square of correlation coefficient $r^{2}=0.954$.

at $550 \mathrm{~nm}$ is due to an equilibrium of two strong non-linear absorption processes of plant pigments in the red and blue regions [2-4]. Near $700 \mathrm{~nm}$ the processes of Chl absorption and scattering by a leaf are also in an equilibrium. 
Table. The algorithms for total Chl determination in leaves, having the form $\mathrm{Chl}=\mathrm{a}+\mathrm{b}^{*} \mathbf{R}_{750} / \mathbf{R}_{\mathbf{x}}$. Est. err., is estimation error of $\mathrm{Chl}, \mathrm{r}$ is the correlation coefficient and $\mathrm{n}$ is number of samples measured. Est.err. and a are given in $\mathrm{nmol} / \mathrm{cm}^{2}$.

\begin{tabular}{|l|c|c|c|c|c|c|c|c|c|}
\hline \multirow{2}{*}{ Leaves } & $\mathbf{n}$ & \multicolumn{4}{|c|}{$\mathbf{R}_{750} / \mathbf{R}_{550}$} & \multicolumn{4}{c|}{$\mathbf{R}_{750} / \mathbf{R}_{700}$} \\
\cline { 3 - 9 } & & $\mathrm{r}^{2}$ & $\mathrm{a}$ & $\mathrm{b}$ & Est.err. & $\mathrm{r}^{2}$ & $\mathrm{a}$ & $\mathrm{b}$ & Est.err. \\
\hline tobacco [7] & 13 & 0.95 & -12.36 & 15.79 & 2.59 & 0.95 & -11.31 & 12.91 & 2.54 \\
chestnut & 25 & 0.90 & -11.72 & 12.74 & 5.97 & 0.92 & -9.39 & 1.82 & 5.38 \\
maple & 31 & 0.89 & -11.62 & 13.75 & 4.53 & 0.92 & -11.72 & 13.65 & 3.89 \\
cotoneatser & 8 & 0.98 & -24.73 & 21.11 & 3.21 & 0.98 & -20.36 & 18.48 & 3.14 \\
\hline
\end{tabular}
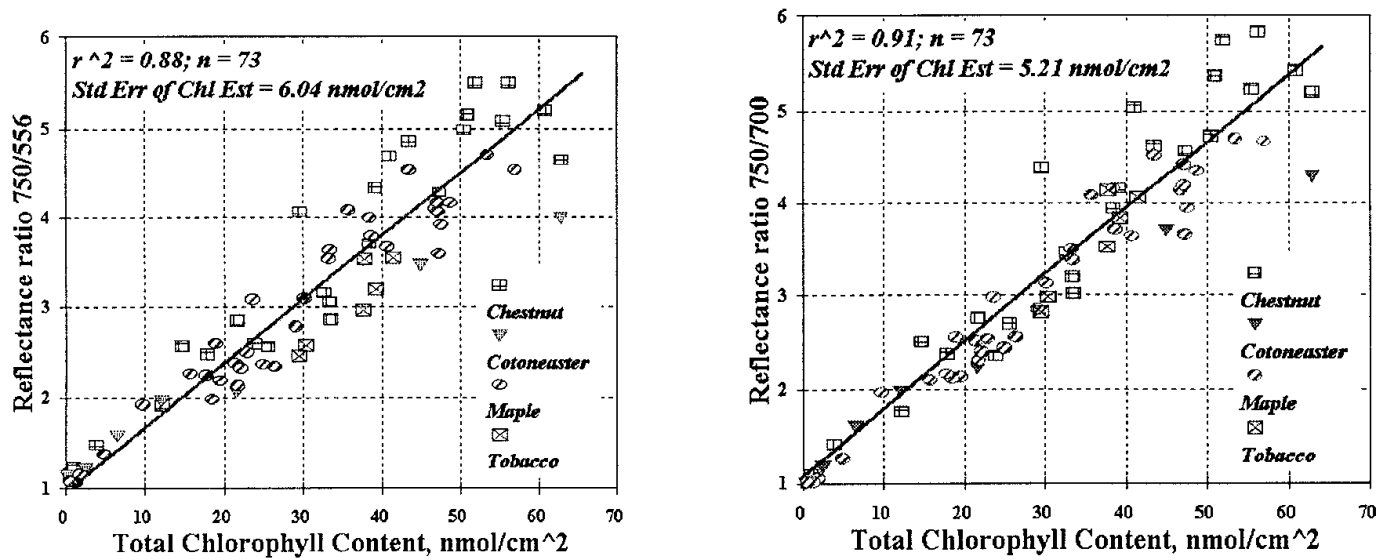

Fig. 5. Reflectance ratios $\mathrm{R}_{750} / \mathrm{R}_{550}$ and $\mathrm{R}_{750} / \mathrm{R}_{700}$ versus analytically measured chlorophyll content Data for tobacco leaves were taken from Lichtenthaller et al., 1996 [7].

Similar behavior of reflectances near $500 \mathrm{~nm}$ and 670 $\mathrm{nm}$ (with very small variation and sensitivity to changing in Chl content) was observed for yellowish-green to dark green leaves $\left(\mathrm{Chl}>5 \mathrm{nmol} / \mathrm{cm}^{2}\right)$. The correlation was very high with determination coefficient $r^{2}=0.954$ (Fig. 4).

Several functions of reflectance directly proportional to Chl content have been found and novel and effective algorithms for estimation of pigment contents in leaves were introduced. These algorithms provide precise estimation of $\mathrm{Chl}$ in the leaves with a wide range of the pigment variation (total Chl from 0.6 to more than $56 \mathrm{nmol} / \mathrm{cm}^{2}$ ). The results of application of two algorithms $\left(\mathrm{R}_{750} / \mathrm{R}_{556}\right.$ and $\left.\mathrm{R}_{750} / \mathrm{R}_{700}\right)$ utilizing spectral regions with maximal (reflectances near 550 and $700 \mathrm{~nm}$ ) and minimal (reflectance at $750 \mathrm{~nm}$ was used as a reference) sensitivity to chlorophyll variations in the leaves are shown in Figs. 5 and in Table.

\section{REFERENCES}

[1] E.W. Chappelle, M. S. Kim, and J. E. McMurtrey, III, "Ratio analysis of reflectance spectra (RARS): An algorithm for the remote estimation of the concentrations of chlorophyll $a$, chlorophyll $b$, and carotenoids in soybean leaves," Remote Sens. Environ., vol. 39, pp. 239$247,1992$.
[2] A.Gitelson and M.N. Merzlyak, "Spectral reflectance changes associated with autumn senescence of Aesculus hippocastanum L. and Acer platanoides L. leaves. Spectral features and relation to chlorophyll estimation," J. Plant Physiol., vol. 143, pp. 286-292, 1994.

[3] A. Gitelson and M.N. Merzlyak, "Quantitative estimation of chlorophyll- $a$ using reflectance spectra: Experiments with autumn chestnut and maple leaves," J. Photochem. Photobiol.(B), vol. 22, pp. 247-252, 1994.

[4] A. Gitelson and M. Merzlyak, Signature analysis of leaf reflectance spectra: algorithm development for remote sensing of chlorophyll. J.Plant Physiol.,1996, in press.

[5] A. Gitelson, Y.J. Kaufman and M.N. Merzlyak, "Green atmospherically resistant vegetation index for EOSMODIS," Remote Sens. Environ., 1996, in press.

[6] A. Gitelson, M.N. Merzlyak, and H.K., Lichtenthaler, "Detection of red edge position and chlorophyll content by reflectance measurements near $700 \mathrm{~nm}$," J. Plant Physiol., 1996, in press.

[7] H.K. Lichtenthaler, A.A. Gitelson and M. Lang, "Nondestructive determination of chlorophyll content of leaves of a green and an aurea mutant of tobacco by reflectance measurements," J. Plant Physiol., 1996, in press. 